\title{
Peritoneal water transport characteristics of diabetic patients undergoing peritoneal dialysis: a longitudinal study
}

\author{
Ana Fernandes, ${ }^{a}$ Roi Ribera-Sanchez,b Ana Rodríguez-Carmona, ${ }^{\mathrm{b}}$ Antía López- \\ Iglesias, ${ }^{\mathrm{b}}$ Natacha Leite-Costa, ${ }^{\mathrm{b}}$ Miguel Pérez Fontán ${ }^{\mathrm{b}, \mathrm{c}}$ \\ ${ }^{a}$ Division of Nephrology, Centro Hospitalar de Setúbal, Setúbal, Portugal; ${ }^{b}$ Division of Nephrology, University \\ Hospital A Coruña, and ${ }^{c}$ Institute of Biomedical Research (INIBIC), Health Sciences Faculty, University of A \\ Coruña, A Coruña, Spain
}

\begin{abstract}
Background: Volume overload is frequent in diabetics undergoing peritoneal dialysis (PD), and may play a significant role in the excess mortality observed in these patients. The characteristics of peritoneal water transport in this population have not been studied sufficiently.

Method: Following a prospective, single-center design we made cross-sectional and longitudinal comparisons of peritoneal water transport in 2 relatively large samples of diabetic and nondiabetic PD patients. We used $3.86 / 4.25 \%$ glucose-based peritoneal equilibration tests (PET) with complete drainage at $60 \mathrm{~min}$, for these purposes.

Main Results: We scrutinized 59 diabetic and 120 nondiabetic PD patients. Both samples showed relatively similar characteristics, although diabetics were significantly more overhydrated than nondiabetics. The baseline PET disclosed lower ultrafiltration (mean $439 \mathrm{~mL}$ diabetics vs. $532 \mathrm{~mL}$ nondiabetics, $p=0.033$ ) and sodium removal (41 vs. $53 \mathrm{mM}, p=0.014$ ) rates in diabetics. One hundred and nine patients (36 diabetics) underwent a second PET after 12 months, and 45 (14 diabetics) underwent a third one after 24 months. Longitudinal analyses disclosed an essential stability of water transport in both groups, although nondiabetic patients showed a trend where an increase in free water transport $(p=0.033)$ was observed, which was not the case in diabetics. Conclusions: Diabetic patients undergoing PD present lower capacities of ultrafiltration and sodium removal than their nondiabetic counterparts. Longitudinal analyses disclose an essential stability of water transport capacities, both in diabetics and nondiabetics. The clinical significance of these differences deserves further analysis.
\end{abstract}

\section{Keywords}

Peritoneal dialysis; Diabetes mellitus; Ultrafiltration; Free; Water transport; Small solute transport; Overhydration 


\section{Introduction}

Diabetes mellitus (DM) has become the leading cause of end-stage kidney disease (ESKD) worldwide [1] . Diabetic patients with ESKD undergo an increased risk or mortality related, for the most part, to a high incidence of cardiovascular events $[2,3]$.

The compared outcomes of diabetic ESKD patients treated with peritoneal dialysis (PD) or hemodialysis are a matter of controversy. The results of several large studies [4-9] have suggested that PD may have higher risk of mortality in older, comorbid diabetics, while the outcomes may be more equilibrated, or even favorable to PD, for younger, non-comorbid patients. Some detrimental consequences of long-term PD, including metabolic disorders and chronic volume overload, could contribute to the reported handicap of PD in high-risk subsets of diabetics on dialysis. Variable degrees of volume overload are frequent in patients on PD, even at inception of therapy [10], and prevalent PD patients may be more overhydrated than matched control populations undergoing hemodialysis [11]. The reasons for these findings are complex, but decline of residual kidney function and disorders of peritoneal water transport, either present at baseline or those that appear during the course of treatment, may play significant roles. How these factors perform in the specific case of diabetics is another controversial issue. Previous studies comparing the characteristics of peritoneal transport in diabetics and nondiabetics are surprisingly scarce, and have yielded conflicting results $[12,13]$. In particular, few studies have investigated the time course of peritoneal function, and more specifically of water transport, in these patients. The modified peritoneal equilibration test (PET) with hypertonic glucosebased dialysate and complete drainage at 60 min may represent an appropriate tool to clarify these questions [14].

We have undertaken a prospective, observational study, with the main objective of comparing the characteristics of peritoneal water transport in a relatively large sample of diabetics undergoing chronic PD therapy in a single center.

\section{Population and Method}

\section{General Description}

Following an observational, prospective design, we investigated all patients treated with PD in the University Hospital of A Coruna (Spain) between July 2009 and December 2016. We accepted to include patients incident or prevalent on this therapy. Our main purpose was to compare the characteristics of peritoneal water transport in diabetic and nondiabetic patients, using the modified PET with complete drainage at $60 \mathrm{~min}$ as the main instrument of the study, which we performed at baseline, and then yearly during-follow-up. We performed both cross-sectional and longitudinal analyses to disclose a potentially differentiated impact of diabetes on the outcome of peritoneal membrane function.

The main outcome variables were peritoneal ultrafiltration (UF) and its fractions (free water transport [FWT] and small pore UF), during PET. For incident patients, follow-up was started since the baseline PET, performed during the second month of PD therapy, while for prevalent patients, the starting point was the first scheduled PET during the study period.

The study complied with the ethical requirements for observational, prospective studies in our center. Oral informed consent was obtained from all participating patients. 


\section{Population}

We considered for the study all patients incident or prevalent on PD during the above-mentioned period. Exclusion criteria included:

- Age younger than 18 years

- Peritoneal infection, abdominal surgery or significant hemoperitoneum less than 3 months before the initiation of the study

- Major clinical event less than 3 months before the initiation of the study

- Expected death or kidney transplantation $<6$ months after the initiation of the study

- Inability to provide informed consent for the study

- Unwillingness to participate in the study

- For longitudinal analysis we included only patients with at least 2 yearly PET studies.

\section{Study Variables}

Summary variables were obtained at the time the baseline PET was performed. These included time on dialysis, previous episodes of peritoneal infection, urea distribution volume (Watson), bioelectrical impedance analysis (BIA) (BCM, Fresenius Medical Care, Bad Homburg, Germany), systolic blood pressure and diastolic blood pressure (at the time of PET study), serum $\mathrm{C}$ reactive protein (immunoturbidimetry), serum albumin (autoanalyzer), mean daily UF (clinical records), glomerular filtration rate (mean of urea and creatinine renal clearances), $\mathrm{Kt} / \mathrm{V}$ and estimated protein intake (PD Adequest software, Baxter, Deerfield, Illinois, USA), proteinuria, daily peritoneal protein excretion (pyrogalol red), drug therapies (including diuretics, renin-angiotensin-aldosterone axis antagonists and statins), and PD prescription conditions (peritoneal glucose load, icodextrin, amino acid-based solutions).

A standard, modified PET with $3.86 \%$ glucose-based dialysate and complete drainage at $60 \mathrm{~min}$ was performed at baseline, and then repeated on a yearly basis until the end of follow-up. The test was performed after an overnight $2.27 \%$ glucose-based exchange, using the patient's usual dwell volume. The abdominal cavity was drained for at least $20 \mathrm{~min}$, with the patient in the sitting and then in the upright position. Dextrose-based dialysate $(3.86 \%)$ was then instilled, with the patient rolling from side to side every few minutes to promote intraperitoneal mixing of dialysate; dialysate samples were collected at times 0, 60 (complete drainage), 120, and $240 \mathrm{~min}$, and a blood sample was collected at the start of the procedure. All blood and dialysate samples were sent to the central laboratory and processed within $24 \mathrm{~h}$. Dialysate concentration of creatinine was corrected for interference with glucose in the effluent. The D/P creatinine at $240 \mathrm{~min}(\mathrm{D} / \mathrm{PCr})$ was calculated as the ratio of the dialysate concentration of creatinine at $240 \mathrm{~min}$ to the serum concentration, the D/D0 glucose at $240 \mathrm{~min}(\mathrm{D} / \mathrm{D} 0 \mathrm{~g})$ was calculated as the ratio of dialysate concentration of glucose at 240 min to time 0 , and the UF volume was calculated from the difference in the weights of the bag before and after the test. The following PET parameters were recorded: D/PCr, D/D0g, UF at 60 min and 240 min, small pore UF and FWT, the latter corrected for diffusion [15], sodium sieving at $60 \mathrm{~min}$, total sodium removal during PET (mass balance) and peritoneal protein excretion. In the case of diabetic patients, finger prick blood glucose levels were estimated at 0,120 , and $240 \mathrm{~min}$, and subcutaneous short-acting insulin was administered, as needed.

\section{Data Analysis}

Numerical variables are presented as mean values \pm SD or median values with range, as needed. Categorical variables are presented as total number and percentages.

We first compared the results of the baseline PET in diabetics and nondiabetics, overall and separately for incident and prevalent patients. We used Student $t$ test, analysis of variance, MannWhitney's test, $\chi^{2}$ distribution, Fisher's exact test, and Spearman's correlation coefficient, for these comparisons. To counteract potential imbalances between the compared populations, we applied 
forward multiple regression analysis, controlling for 3 covariates for peritoneal transport rates, namely, age, serum C-reactive protein and time on PD. In a second step, we compared the time course of peritoneal transport in the study groups. For this purpose, we applied a paired analysis strategy, using repeated measures analysis of variance to check variations over time in the same cohorts.

The statistical significance level was set at 0.05 . All analyses were performed with the SPSS 22.0 statistical software.

\section{Results}

\section{Overview}

One hundred and seventy nine patients were included in the study. The essential characteristics of the study population at baseline are presented in Tables 1 and 2 . The mean glycated hemoglobin in diabetic patients was $6.6 \pm 1.3 \%$, at baseline Incident diabetics were comparable to incident nondiabetics, except for an older age $(65.8 \pm 10.2$ vs. $58.8 \pm 15.2$ years, $p=0.015)$ and a higher degree of overhydration during the baseline BIA study $(1.9 \pm 1.5$ vs. $0.9 \pm 1.6 \mathrm{~L}, p=0.004$; all other variables in Tables 1, 2 not significant [NS] for this subgroup). On the other hand, we also observed some minor differences at baseline between prevalent patients with or without diabetes, including glomerular filtration rate $(6.6 \pm 4.2$ vs. $4.3 \pm 3.3 \mathrm{~mL} / \mathrm{min}$, respectively, $p=0.015)$ and fat tissue mass (BIA; $15.1 \pm 4.4$ vs. $12.7 \pm 3.1 \mathrm{~kg}, p=0.02$ ).

Table 1. Baseline characteristics of the study population

\begin{tabular}{|c|c|c|c|}
\hline & Diabetes $(n=59)$ & No diabetes $(n=120)$ & $p$ value \\
\hline Age, years, mean \pm SD & $63.1 \pm 14.7$ & $58.7 \pm 15.5$ & 0.16 \\
\hline Gender, men, $\%$ & 76.3 & 65.0 & 0.14 \\
\hline Time on in dialysis, months, mean $\pm \mathrm{SD}$ & $11.2 \pm 18.0$ & $14.9 \pm 22.5$ & 0.27 \\
\hline \multicolumn{4}{|l|}{ Cause of ESKD, \% } \\
\hline Diabetes & 84.7 & 0 & 0.0005 \\
\hline Glomerular disease & 3.4 & 20.0 & \\
\hline Interstitial disease & 0 & 7.5 & \\
\hline Cystic & 0 & 10.8 & \\
\hline Systemic & 3.4 & 7.5 & \\
\hline Vascular & 1.7 & 10.8 & \\
\hline Undetermined & 6.8 & 43.4 & \\
\hline Charlson's comorbidity score, mean \pm SD & $7.9 \pm 2.2$ & $5.8 \pm 2.5$ & 0.001 \\
\hline Incident/prevalent, $\%$ & $67.8 / 32.2$ & $60.0 / 40.0$ & 0.22 \\
\hline Number of previous peritonitis, mean \pm SD & $0.42 \pm 1.01$ & $0.47 \pm 1.03$ & 0.77 \\
\hline \multicolumn{4}{|l|}{ Modality of PD, $\%$} \\
\hline Manual & 83.1 & 78.3 & 0.73 \\
\hline Automated & 16.9 & 21.7 & \\
\hline Use of amino acid-based solutions, $\%$ & 27.1 & 20.0 & 0.21 \\
\hline Use of icodextrin, $\%$ & 69.5 & 59.2 & 0.18 \\
\hline Peritoneal glucose load, g/24 h, mean \pm SD & $87.2 \pm 43.5$ & $78.2 \pm 42.0$ & 0.14 \\
\hline Statins, $\%$ & 84.7 & 62.5 & 0.003 \\
\hline RAAS antagonists, $\%$ & 54.2 & 38.3 & 0.034 \\
\hline Furosemide, $\%$ & 69.4 & 59.2 & 0.08 \\
\hline
\end{tabular}

ESKD, end-stage kidney disease; PD, peritoneal dialysis; RAAS, renin-angiotensin-aldosterone system. 
Table 2. Laboratory, adequacy, and clinical characteristics of the patients at baseline evaluation

\begin{tabular}{|c|c|c|c|}
\hline & Diabetes $(n=59)$ & No diabetes $(n=120)$ & $p$ value \\
\hline \multicolumn{4}{|l|}{ Laboratory } \\
\hline Sodium, $\mathrm{mmol} / \mathrm{L}$ & $138 \pm 3.2$ & $139 \pm 3.4$ & 0.16 \\
\hline Albumin, g/dL & $3.6 \pm 0.4$ & $3.7 \pm 0.5$ & 0.45 \\
\hline C-reactive protein, $\mathrm{mg} / \mathrm{dL}$ & $0.53(0.01 / 6.34)$ & $0.47(0.01 / 8.32)$ & 0.30 \\
\hline \multicolumn{4}{|l|}{ Anthropometric } \\
\hline Urea distribution volume, $\mathrm{L}$ & $37.8 \pm 5.3$ & $36.6 \pm 7.0$ & 0.44 \\
\hline \multicolumn{4}{|l|}{ Body composition (bioimpedance) } \\
\hline Fat body mass, $\mathrm{kg}$ & $14.6 \pm 4.5$ & $12.6 \pm 4.0$ & 0.01 \\
\hline Lean body mass, $\mathrm{kg}$ & $12.9 \pm 2.5$ & $13.8 \pm 3.5$ & 0.09 \\
\hline Intra/extracellular water & $1.02 \pm 0.11$ & $1.00 \pm 0.19$ & 0.70 \\
\hline Intracellular water, L & $18.9 \pm 4.7$ & $18.9 \pm 4.7$ & 0.30 \\
\hline Extracellular water, L & $16.7 \pm 3.3$ & $17.8 \pm 2.8$ & 0.06 \\
\hline Overhydration, L & $1.9 \pm 1.6$ & $0.9 \pm 1.4$ & 0.0005 \\
\hline \multicolumn{4}{|l|}{ Blood pressure, $\mathrm{mm} \mathrm{Hg}$} \\
\hline Systolic & $138.3 \pm 19.8$ & $130.2 \pm 20.3$ & 0.012 \\
\hline Diastolic & $74.6 \pm 12.9$ & $76.9 \pm 13.1$ & 0.28 \\
\hline \multicolumn{4}{|l|}{ Residual kidney function } \\
\hline Diuresis & $1,424 \pm 623$ & $1,249 \pm 878$ & 0.13 \\
\hline GFR, $\mathrm{mL} / \mathrm{min}$ & $8.4 \pm 4.0$ & $6.3 \pm 4.0$ & 0.02 \\
\hline \multicolumn{4}{|l|}{ Adequacy } \\
\hline 24-h ultrafiltration, $\mathrm{mL}$ & $744 \pm 330$ & $819 \pm 412$ & 0.31 \\
\hline $\mathrm{Kt} / \mathrm{V}$ & $2.41 \pm 0.61$ & $2.31 \pm 0.57$ & 0.22 \\
\hline \multicolumn{4}{|l|}{ Protein metabolism } \\
\hline nPNA, g/kg & $1.22 \pm 0.29$ & $1.21 \pm 0.27$ & 0.84 \\
\hline Proteinuria, g/24 h & $1.7 \pm 1.3$ & $1.3 \pm 1.5$ & 0.096 \\
\hline Peritoneal protein excretion, $\mathrm{g} / 24 \mathrm{~h}$ & $6.4 \pm 2.4$ & $6.1 \pm 2.1$ & 0.50 \\
\hline
\end{tabular}

GFR, glomerular filtration rate (mean renal clearance); nPNA, normalized protein nitrogen appearance.

Figures denote mean $\pm \mathrm{SD}$ or median value with range (C-reactive protein).

All patients underwent a baseline PET. One hundred and nine underwent a second PET 1 year later, and 45 had a third PET study 2 years later. The reasons for patient censoring during follow-up are presented in Table 3.

Table 3. Reasons for censoring for follow-up PETs

\begin{tabular}{lcc}
\hline & Diabetes & No diabetes \\
\hline & & \\
Patients who did not undergo a $2^{\text {nd }}$ & & \\
PET study & $8(13.6)$ & $10(8.3)$ \\
Death & $5(8.4)$ & $17(14.2)$ \\
Kidney transplantation & $2(3.4)$ & $5(4.2)$ \\
PD drop-out & $8(13.6)$ & $15(12.6)$ \\
Follow-up <12 months & & \\
Patients who did not undergo a $3^{\text {rd }}$ & & \\
PET study & $12(20.3)$ & $12(10.0)$ \\
Death & $5(8.5)$ & $13(10.9)$ \\
Kidney transplantation & $2(3.4)$ & $5(4.2)$ \\
PD drop-out & $4(6.8)$ & $10(8.4)$ \\
Follow-up <24 months & & \\
& & \\
\hline
\end{tabular}

Figures denote number of patients $(\%)$. 


\section{Cross-Sectional Comparisons}

Comparative values of baseline peritoneal transport characteristics in diabetics and nondiabetics are presented in Table 4. Most differences were subtle, although we observed clear trends to lower UF and sodium removal rates at $240 \mathrm{~min}$ in diabetics. Interestingly, the same differences persisted on cross-sectional comparisons 1 year later (Table 5). Multivariate analyses of baseline data confirmed that after controlling for age, C-reactive protein, and time on $\mathrm{PD}$, diabetics still presented lower rates of UF at $240 \mathrm{~min}(\mathrm{~B}=-110.1 \mathrm{~mL}, 95 \% \mathrm{CI}-219.1 /-9.33, p=0.024)$ and sodium removal during PET $(\mathrm{B}=-14.5 \mathrm{~m} \mathrm{M}, 95 \% \mathrm{CI}-25.5 /-2.8, p=0.018$; other variables NS). Comparisons made in separate for incident and prevalent patients disclosed similar, nonsignificant trends, seemingly due to the expected loss of statistical power (data not shown).

Table 4. Results of the baseline PET

\begin{tabular}{|c|c|c|c|}
\hline & Diabetes $(n=59)$ & No diabetes $(n=120)$ & $p$ value \\
\hline Ultrafiltration, $60 \mathrm{~min}, \mathrm{~mL}$ & $295.4 \pm 159.5$ & $303.4 \pm 180.1$ & 0.88 \\
\hline Ultrafiltration, $240 \mathrm{~min}, \mathrm{~mL}$ & $438.6 \pm 243.3$ & $531.5 \pm 281.1$ & 0.033 \\
\hline Ultrafiltration $<400 \mathrm{~mL}$ at $240 \mathrm{~min}, \%$ & 45.8 & 31.7 & 0.07 \\
\hline Free water transport, $60 \mathrm{~min}$ (corrected), $\mathrm{mL}$ & $171.6 \pm 83.6$ & $173.0 \pm 68.9$ & 0.91 \\
\hline Small pore ultrafiltration, $60 \mathrm{~min}, \mathrm{~mL}$ & $154.1 \pm 127.8$ & $163.2 \pm 140.6$ & 0.70 \\
\hline Sodium sieving, $60 \mathrm{~min}, \mathrm{mM}$ & $8.3 \pm 3.8$ & $7.8 \pm 3.7$ & 0.33 \\
\hline Total sodium removal during PET, mM & $40.9 \pm 28.0$ & $53.0 \pm 31.5$ & 0.014 \\
\hline Peritoneal protein excretion, PET, mg & $1,584 \pm 550$ & $1,517 \pm 512$ & 0.32 \\
\hline D60/D0 glucose & $0.71 \pm 0.18$ & $0.73 \pm 0.14$ & 0.51 \\
\hline D120/D0 glucose & $0.55 \pm 0.15$ & $0.56 \pm 0.13$ & 0.49 \\
\hline D240/D0 glucose & $0.32 \pm 0.11$ & $0.32 \pm 0.10$ & 0.98 \\
\hline $\mathrm{D} / \mathrm{P}$ creatinine $60^{\prime}$ & $0.39 \pm 0.11$ & $0.37 \pm 0.10$ & 0.36 \\
\hline $\mathrm{D} / \mathrm{P}$ creatinine 120 & $0.52 \pm 0.11$ & $0.52 \pm 0.10$ & 0.88 \\
\hline D/P creatinine 240 & $0.70 \pm 0.11$ & $0.70 \pm 0.10$ & 0.90 \\
\hline
\end{tabular}

Figures denote mean $\pm \mathrm{SD}$, except percentage of patients with UF failure.

D/D0, dialysate glucose at 60 (D60/D0), 120 (D120/D0) or 240 (D240/D0) min vs. the dialysate glucose at time zero. D/P creatinine: dialysate-to-plasma creatinine concentration ratio at 60,120 , and $240 \mathrm{~min}$. 
Table 5. Results of the second and third PET studies

\begin{tabular}{|c|c|c|c|c|c|c|}
\hline & \multicolumn{3}{|c|}{ Second PET $(n=109)$} & \multicolumn{3}{|c|}{ Third PET $(n=41)$} \\
\hline & $\begin{array}{l}\text { diabetes } \\
(n=36)\end{array}$ & $\begin{array}{l}\text { no diabetes } \\
\quad(n=73)\end{array}$ & $p$ value & $\begin{array}{l}\text { diabetes } \\
(n=14)\end{array}$ & $\begin{array}{l}\text { no diabetes } \\
\quad(n=33)\end{array}$ & $p$ value \\
\hline $\mathrm{UF}, 60^{\prime}, \mathrm{mL}$ & $255.2 \pm 169.0$ & $313.1 \pm 169.5$ & 0.08 & $223.1 \pm 150.9$ & $282.2 \pm 134,9$ & 0.14 \\
\hline $\mathrm{UF}, 240^{\prime}, \mathrm{mL}$ & $425.0 \pm 244.6$ & $545.8 \pm 260.9$ & 0.008 & $417.9 \pm 230.1$ & $482.1 \pm 224.0$ & 0.30 \\
\hline $\mathrm{UF}<400 \mathrm{~mL}$ at $240, \%$ & 51.3 & 26.4 & 0.003 & 42.9 & 30.3 & 0.25 \\
\hline FWT, 60', mL & $163.3 \pm 75.8$ & $188.8 \pm 96.3$ & 0.20 & $170.1 \pm 80.1$ & $166.6 \pm 80.9$ & 0.68 \\
\hline SPUF, 60', mL & $129.3 \pm 145.6$ & $147.7 \pm 123.3$ & 0.28 & $70.1 \pm 112.3$ & $130.5 \pm 111.7$ & 0.27 \\
\hline Na sieving, $60^{\prime}, \mathrm{mM}$ & $8.3 \pm 3.6$ & $9.1 \pm 4.4$ & 0.27 & $8.6 \pm 3.2$ & $9.2 \pm 3.7$ & 0.61 \\
\hline Total Na removal, $\mathrm{mM}$ & $38.7 \pm 29.3$ & $51.8 \pm 20.6$ & 0.029 & $37.7 \pm 29.9$ & $46.1 \pm 22.8$ & 0.49 \\
\hline Peritoneal protein excretion, $\mathrm{mg}$ & $1,587 \pm 458$ & $1,399 \pm 555$ & 0.16 & $1,444 \pm 820$ & $1,190 \pm 555$ & 0.44 \\
\hline D60/D0 glucose & $0.72 \pm 0.15$ & $0.78 \pm 0.14$ & 0.19 & $0.70 \pm 0.12$ & $0.76 \pm 0.12$ & 0.14 \\
\hline D120/D0 glucose & $0.56 \pm 0.16$ & $0.60 \pm 0.14$ & 0.16 & $0.56 \pm 0.12$ & $0.61 \pm 0.13$ & 0.30 \\
\hline D240/D0 glucose & $0.34 \pm 0.12$ & $0.34 \pm 0.11$ & 0.94 & $0.34 \pm 0.09$ & $0.37 \pm 0.12$ & 0.50 \\
\hline $\mathrm{D} / \mathrm{P}$ creat $60^{\prime}$ & $0.38 \pm 0.10$ & $0.37 \pm 0.10$ & 0.44 & $0.36 \pm 0.10$ & $0.34 \pm 0.10$ & 0.40 \\
\hline $\mathrm{D} / \mathrm{P}$ creat $120^{\prime}$ & $0.52 \pm 0.11$ & $0.52 \pm 0.11$ & 0.98 & $0.51 \pm 0.11$ & $0.52 \pm 0.10$ & 0.53 \\
\hline D/P creat $240^{\prime}$ & $0.71 \pm 0.10$ & $0.70 \pm 0.12$ & 0.77 & $0.73 \pm 0.10$ & $0.67 \pm 0.11$ & 0.11 \\
\hline
\end{tabular}

Figures denote mean $\pm \mathrm{SD}$, except percentage of patients with UF failure.

UF, ultrafiltration; FWT, free water transport (corrected); SPUF, small pore ultrafiltration; D/D0, dialysate glucose at 60 (D60/D0), 120 (D120/D0) or 240 (D240/D0) min vs. the dialysate glucose at time zero. D/P creatinine: dialysate-to-plasma creatinine concentration ratio at 60,120 , and $240 \mathrm{~min}$.

For the whole group of patients, the degree of overhydration (BIA) correlated significantly with $\mathrm{UF}$ at $240 \mathrm{~min}$, both at baseline $(r=-0.18, p=0.037)$ and during the second PET $(r=-0.34, p=$ $0.002)$, and the same applied for $\mathrm{D} / \mathrm{P}$ creatinine $(r=-0.46, p=0.001$ at baseline; $r=-0.46, p=0.002$ second PET) and D/D0 glucose at $240 \min (r=0.32, p=0.003$ at baseline; $r=0.43, p=0.001$ second PET; Spearman).

PET-related hyperglycemia was relatively frequent in diabetics. During the baseline PET, glycemia was $>200 \mathrm{mg} / \mathrm{dL}$ in 6 patients $(11.1 \%)$, and $>300 \mathrm{mg} / \mathrm{dL}$ in 3 cases $(5.6 \%)$. At $120 \mathrm{~min}, 20$ patients $(37.0 \%)$ presented glycemia $>200 \mathrm{mg} / \mathrm{dL}$, and $6(11.1 \%),>300 \mathrm{mg} / \mathrm{dL}$. After $240 \mathrm{~min}, 16$ patients (29.6\%) still had glycemia >200 mg/dL, and 4 (7.4\%), >300 mg/dL. Remarkably, we found no correlation between glycemia at $120 \mathrm{~min}$ and UF obtained at $60 \mathrm{~min}(r=-0.07, p=0.90)$ or 240 $\min (r=-0.19, p=0.30)$, in these patients.

\section{Longitudinal Comparisons}

Fourteen diabetics $(38.9 \%)$ and 28 nondiabetics $(38.5 \%)$ presented at least one episode of peritoneal infection between the baseline and the second PET $(p=0.95)$, and 5 diabetics $(35.7 \%)$ and 15 nondiabetics $(45.4 \%)$ presented at least one episode of peritoneal infection between the second and third PET studies $(p=0.34)$. Twelve patients changed their PD modality between the first and second PET, basically from continuous ambulatory PD to automated PD. Stratification of incident and prevalent patients did not show differences between diabetics and nondiabetics.

Analysis of the time courses of peritoneal transport characteristics in diabetics (Table 6) and nondiabetics (Table 7) revealed an essential stability in both groups. Interestingly, FWT increased during the first year in nondiabetics but did not change significantly in diabetics. 
Table 6. Longitudinal follow-up of diabetic patients

\begin{tabular}{|c|c|c|c|c|}
\hline & Baseline PET & 2nd year PET & 3rd year PET & $p$ value \\
\hline Ultrafiltration, 60', mL & $272.7 \pm 187.6$ & $306.0 \pm 165.2$ & $213.64 \pm 162.9$ & 0.35 \\
\hline Ultrafiltration, $240^{\prime}, \mathrm{mL}$ & $450.9 \pm 242.3$ & $425.0 \pm 244.6$ & $418.2 \pm 254.2$ & 0.55 \\
\hline Free water transport $60^{\prime}$ (corrected), mL & $170.7 \pm 79.6$ & $161.8 \pm 74.2$ & $171.9 \pm 82.9$ & 0.38 \\
\hline Small pore ultrafiltration, $60^{\prime}, \mathrm{mL}$ & $157.9 \pm 121.2$ & $130.1 \pm 145.6$ & $76.9 \pm 143.3$ & 0.29 \\
\hline $\mathrm{Na}$ sieving, $60^{\prime}, \mathrm{mM}$ & $8.18 \pm 4.5$ & $8.55 \pm 3.80$ & $8.81 \pm 3.31$ & 0.86 \\
\hline Total Na removal, $\mathrm{mM}$ & $50.6 \pm 32.6$ & $42.9 \pm 24.5$ & $38.3 \pm 31.5$ & 0.45 \\
\hline Peritoneal protein excretion, $\mathrm{mg}$ & $1,812.6 \pm 349.3$ & $1,595.2 \pm 440.1$ & $1,496.4 \pm 803.3$ & 0.25 \\
\hline D240/D0 glucose & $0.32 \pm 0.11$ & $0.34 \pm 0.13$ & $0.34 \pm 0.09$ & 0.019 \\
\hline $\mathrm{D} / \mathrm{P}$ creatinine & $2400.69 \pm 0.10$ & $0.71 \pm 0.10$ & $0.71 \pm 0.10$ & 0.98 \\
\hline
\end{tabular}

Figures denote mean $\pm \mathrm{SD}$, except percentage of patients with UF failure.

D240/D0, dialysate glucose at 240 (D240/D0) min vs. the dialysate glucose at time zero. D/P creatinine 240: dialysate-toplasma creatinine concentration ratio at $240 \mathrm{~min}$.

Table 7. Longitudinal follow-up of nondiabetic patients

\begin{tabular}{|c|c|c|c|c|}
\hline & Baseline PET & 2nd year PET & 3rd year PET & $p$ value \\
\hline Ultrafiltration, 60 ', mL & $303.22 \pm 181.0$ & $327.9 \pm 183.8$ & $274.4 \pm 128.8$ & 0.31 \\
\hline Ultrafiltration at $240 \mathrm{~min}, \mathrm{~mL}$ & $541.9 \pm 285.5$ & $544.8 \pm 263.5$ & $491.7 \pm 199.2$ & 0.19 \\
\hline Free water transport $60 \%$ corrected, $\mathrm{mL}$ & $170.1 \pm 66.4$ & $187.7 \pm 96.6$ & $162.6 \pm 86.5$ & 0.03 \\
\hline Small pore ultrafiltration, $60^{\prime}, \mathrm{mL}$ & $165.1 \pm 144.1$ & $145.8 \pm 124.1$ & $145.3 \pm 114.5$ & 0.90 \\
\hline $\mathrm{Na}$ sieving, 60', mM & $7.8 \pm 3.6$ & $10.0 \pm 9.7$ & $53.5 \pm 30.7$ & 0.04 \\
\hline Total Na removal, $\mathrm{mM}$ & $53.5 \pm 30.7$ & $50.8 \pm 27.4$ & $45.4 \pm 23.5$ & 0.42 \\
\hline Peritoneal protein excretion, mg & $1,545.6 \pm 387.0$ & $1,469.5 \pm 387.0$ & $1,469.5 \pm 453.7$ & 0.06 \\
\hline D240/D0 glucose & $0.32 \pm 0.10$ & $0.34 \pm 0.11$ & $0.37 \pm 0.12$ & 0.19 \\
\hline $\mathrm{D} / \mathrm{P}$ creatinine 240 & $0.70 \pm 0.10$ & $0.70 \pm 0.12$ & $0.70 \pm 0.12$ & 0.36 \\
\hline
\end{tabular}

Figures denote mean $\pm \mathrm{SD}$, except percentage of patients with UF failure.

D240/D0, dialysate glucose at 240 (D240/D0) min vs. the dialysate glucose at time zero. D/P creatinine 240: dialysate-toplasma creatinine concentration ratio at $240 \mathrm{~min}$.

When patients were stratified according to time on dialysis, we observed that prevalent, but not incident patients, showed trends to a decrease in UF at $60 \mathrm{~min}(p=0.03)$, sodium sieving $(p=0.013)$ and protein removal $(p=0.047)$, between the baseline and second PETs. These trends were similarly apparent for diabetic and nondiabetic patients.

\section{Discussion}

It has long been recognized that there is a large variability in the characteristics of water and solute transport across the peritoneal membrane and that in some individuals, these conditions change over time [16-19]. This variability may have important clinical consequences, and monitoring these parameters is essential, to guide prescription and improve patient outcomes [20].

Several studies have compared small solute transport characteristics in diabetic and nondiabetic patients undergoing PD, with conflicting results. Some groups have detected faster transport rates in diabetics [21-24], while others have not observed differences with nondiabetics [12, 18, 25]. On the other hand, studies comparing peritoneal water transport characteristics in these 2 groups are remarkably scarce. Chou et al. [12] did not detect a difference in the capacity of UF of 40 diabetics and 122 nondiabetics, either incident or prevalent on PD. However, the authors estimated this parameter using the classic 2.27/2.5\% glucose-based PET, which may not be accurate for this purpose. As expected, UF fractions could not be scrutinized in this study. Using the Standard Peritoneal Permeability Analysis method, Serlie et al. [13] compared peritoneal transport in 11 diabetic and 11 nondiabetic patients starting PD. The observed transcapillary UF rate was lower in 
diabetics. Smit et al. [26] evaluated FWT in, 10 diabetic and 10 nondiabetic patients at the start of PD. They did not detect differences in net UF, fluid absorption, FWT, or peritoneal small solute transport rates between the study groups. Finally, Graff et al. [27] reported no differences in the clearance of albumin, overall PET results or UF capacity in diabetics and nondiabetics. In this particular case, patients were not stratified according to time on PD.

In our study, baseline comparisons disclosed a lower capacity of UF and sodium removal in diabetic than in nondiabetic patients, while small solute transport rates were similar in both groups. Neither did we observe a different distribution of water transport across small and ultrasmall pores (Table 4). These compared features persisted after 1 year of follow-up (Table 5). The reasons for these apparent discrepancies are not clear. It could be tempting to attribute them to the effects of the diabetic milieu on the peritoneum, but this explanation may be speculative because the well-known toxicity of intraperitoneal glucose for the peritoneal membrane [28] cannot be directly extrapolated to the case of DM-related hyperglycemia. In their classic study, Williams et al. [29] did not detect differences in the interstitial and vascular changes observed in peritoneal biopsies from diabetic and nondiabetic patients on PD. On the contrary, a more recent study [30] detected an increased thickness of the submesothelial space and a higher capillary density in peritoneal biopsies from diabetics starting PD. These changes could exert an additive effect to impair transperitoneal water transport, with less predictable effects on small solute transport, which essentially agrees with our results. On the other hand, PET-related hyperglycemia in diabetics could provide an alternative explanation for our findings by reducing the effective osmotic gradient for UF during the test. The design of this study does not permit to clarify this hypothesis, but we were unable to disclose a correlation between PET-related hyperglycemia and UF in our patients with DM. Finally, a higher lymphatic absorption rate in diabetics could also help to explain our observations. Unfortunately, we did not investigate this parameter. The only previous study assessing this question did not detect differences between diabetics and nondiabetics [13].

To our knowledge, there are no previous longitudinal studies evaluating peritoneal water transport characteristics in patients on PD based on the presence or absence of DM. Our data suggest an essential stability over time in both groups (Tables 6,7) in most peritoneal features evaluated, although nondiabetics displayed a trend to an increase in FWT during follow-up, which was not observed in diabetics. These findings are in agreement with previous studies on PD patients overall [31, 32]. Del Peso et al. [33] did not find a different evolution of peritoneal small solute transport rates after 1 year of follow-up in diabetics and nondiabetics.

In this study, overhydration was more frequently observed in diabetic than in nondiabetic patients (Table 2), in agreement with previous reports [10]. The reasons for this difference are seemingly complex, but the lower capacity of UF observed in these patients is a likely contributor. The significant correlation, detected in our patients, between the degree of overhydration, on the one hand, and the observed characteristics of UF and small solute transport, on the other hand, lend support to this hypothesis.

Our study has some significant limitations, including a single-center design. Separate analyses for diabetics and nondiabetics, as also for incident and prevalent patients had a detrimental effect on the statistical power of the analyses. Moreover, a significant proportion of patients were lost during follow-up, a common drawback on longitudinal studies on patients treated with PD. Lack of information on lymphatic reabsorption rates represents another significant limitation. Among the strengths of the study, we should mention here that this is the first study comparing the time course of peritoneal water transport and its fractions in diabetic and nondiabetic PD patients.

In summary, diabetic patients undergoing PD present lower capacities of UF and sodium removal than their nondiabetic counterparts. The time course of water transport characteristics are seemingly similar in both groups, although nondiabetics show a trend to an increase in FWT, which is not observed in nondiabetics. The reasons and potential consequences of these differences deserve further research. 


\section{Acknowledgments}

This study was supported by funds from the Group of Research on Metabolic and Endocrine Diseases of the Institute of Biomedical Research, Health Sciences Faculty, University of A Coruna (Spain).

\section{Disclosure Statement}

We have read and understood the American Journal of Nephrology's policy on conflicts of interest disclosure and declare no conflicts of interest for this study.

\section{References}

1. Passadakis PS, Oreopoulos DG: Diabetic patients on peritoneal dialysis. Semin Dial 2010; 23: 191-197.

2. Kuriyama S: Peritoneal dialysis in patients with diabetes: are the benefits greater than the disadvantages? Perit Dial Int 2007; 27(suppl 2): S190-S195.

3. Chung SH, Han DC, Noh H, Jeon JS, Kwon SH, Lindholm B, et al: Risk factors for mortality in diabetic peritoneal dialysis patients. Nephrol Dial Transplant 2010; 25 : 3742-3748.

4. Vonesh EF, Moran J: Mortality in end-stage renal disease: a reassessment of differences between patients treated with hemodialysis and peritoneal dialysis. J Am Soc Nephrol 1999; 10: 354-365.

5. Heaf JG, Lokkegaard H, Madsen M: Initial survival advantage of peritoneal dialysis relative to haemodialysis. Nephrol Dial Transplant 2002; 17: 112-117.

6. Schaubel DE, Morrison HI, Fenton SS: Comparing mortality rates on CAPD/CCPD and hemodialysis. The Canadian experience: fact or fiction? Perit Dial Int 1998; 18: 478-484.

7. Termorshuizen F, Korevaar JC, Dekker FW, Van Manen JG, Boeschoten EW, Krediet RT: Hemodialysis and peritoneal dialysis: comparison of adjusted mortality rates according to the duration of dialysis: analysis of the Netherlands Cooperative Study on the Adequacy of Dialysis 2. J Am Soc Nephrol 2003; 14: 2851-2860.

8. Collins AJ, Hao W, Xia H, Ebben JP, Everson SE, Constantini EG, et al: Mortality risks of peritoneal dialysis and hemodialysis. Am J Kidney Dis 1999; 34: 1065-1074

9. Vonesh EF, Snyder JJ, Foley RN, Collins AJ: The differential impact of risk factors on mortality in hemodialysis and peritoneal dialysis. Kidney Int 2004; 66: 2389-2401.

10. Ronco C, Verger C, Crepaldi C, Pham J, de los Rios T, Gauly A, et al: Baseline hydration status in incident peritoneal dialysis patients: the initiative of patient outcomes in dialysis (IPOD-PD study) $\dagger$. Nephrol Dial Transplant 2015; 30: 849858.

11. Van Biesen W, Claes K, Covic A, Fan S, Lichodziejewska-Niemierko M, Schoder $\mathrm{V}$, et al: A multicentric, international matched pair analysis of body composition in peritoneal dialysis versus haemodialysis patients. Nephrol Dial Transplant 2013; 28: 2620-2628.

12. Chou MY, Kao MT, Lai MN, Chung SY: Comparisons of the peritoneal equilibration test and ultrafiltration in patients with and without diabetes mellitus on continuous ambulatory peritoneal dialysis. Am J Nephrol 2006; 26: 87-90.

13. Serlie MJ, Struijk DG, de Blok K, Krediet RT: Differences in fluid and solute transport between diabetic and nondiabetic patients at the onset of CAPD. Adv Perit Dial 1997; 13: 29-32.

14. La Milia V: Peritoneal transport testing. J Nephrol 2010; 23: 633-647.

15. Smit W, Struijk DG, Ho-Dac-Pannekeet MM, Krediet RT: Quantification of free water transport in peritoneal dialysis. Kidney Int 2004; 66: 849-854.

16. Struijk DG, Krediet RT, Koomen GC, Boeschoten EW, Hoek FJ, Arisz L: A prospective study of peritoneal transport in CAPD patients. Kidney Int 1994; 45: 1739-1744.

17. Davies SJ: Monitoring of long-term peritoneal membrane function. Perit Dial Int 2001; 21: 225-230.

18. Davies SJ: Longitudinal relationship between solute transport and ultrafiltration capacity in peritoneal dialysis patients. Kidney Int 2004; 66: 2437-2445. 
19. Fernandez Reyes MJ, Bajo MA, del Peso G, Ossorio M, Diaz R, Carretero B, et al: The influence of initial peritoneal transport characteristics, inflammation, and high glucose exposure on prognosis for peritoneal membrane function. Perit Dial Int 2012; 32: 636-644.

20. Mehrotra R, Ravel V, Streja E, Kuttykrishnan S, Adams SV, Katz R, et al: Peritoneal equilibration test and patient outcomes. Clin J Am Soc Nephrol 2015; 10: 1990-2001.

21. Churchill DN, Thorpe KE, Nolph KD, Keshaviah PR, Oreopoulos DG, Page D: Increased peritoneal membrane transport is associated with decreased patient and technique survival for continuous peritoneal dialysis patients. The CANADAUSA (CANUSA) Peritoneal Dialysis Study Group. J Am Soc Nephrol 1998; 9: 1285-1292.

22. Gillerot G, Goffin E, Michel C, Evenepoel P, Biesen WV, Tintillier M, et al: Genetic and clinical factors influence the baseline permeability of the peritoneal membrane. Kidney Int 2005; 67: 2477-2487.

23. Lin JJ, Wadhwa NK, Suh H, Cabralda T, Patlak CS: Increased peritoneal solute transport in diabetic peritoneal dialysis patients. Adv Perit Dial 1995; 11: 63-66.

24. Lamb EJ, Worrall J, Buhler R, Harwood S, Cattell WR, Dawnay AB: Effect of diabetes and peritonitis on the peritoneal equilibration test. Kidney Int 1995; 47: 1760-1767.

25. Lee HB, Park MS, Chung SH, Lee YB, Kim KS, Hwang SD, Moon C: Peritoneal solute clearances in diabetics. Perit Dial Int 1990; 10: 85-88.

26. Smit W, van Esch S, Struijk DG, Krediet RT: Free water transport in patients starting with peritoneal dialysis: a comparison between diabetic and non diabetic patients. Adv Perit Dial 2004; 20: 13-17.

27. Graff J, Fugleberg S, Nielsen SL, Feldt-Rasmussen B: Transperitoneal transport in diabetic and non-diabetic patients on peritoneal dialysis. Clin Physiol 1999; 19: $510-518$.

28. Davies SJ, Mushahar L, Yu Z, Lambie M: Determinants of peritoneal membrane function over time. Semin Nephrol 2011; 31: 172-182.

29. Williams JD, Craig KJ, Topley N, Von Ruhland C, Fallon M, Newman GR, et al: Morphologic changes in the peritoneal membrane of patients with renal disease. $\mathrm{J}$ Am Soc Nephrol 2002; 13: 470-479.

30. Mizumasa T, Hirakata H, Kuroki Y, Katafuchi R, Yotsueda H, Mitsuiki K, Nakashima Y, Tsuruya K: Diabetes influences peritoneal morphology in uremic patients at the initiation of deritoneal dialysis. Perit Dial Int 2013; 33: 175-181.

31. Clerbaux G, Francart J, Wallemacq P, Robert A, Goffin E: Evaluation of peritoneal transport properties at onset of peritoneal dialysis and longitudinal follow-up. Nephrol Dial Transplant 2006; 21: 1032-1039.

32. Coester AM, Smit W, Struijk DG, Krediet RT: Fluid transport with time on peritoneal dialysis: the contribution of free water transport and solute coupled water transport. Contrib Nephrol 2009; 163: 22-26.

33. del Peso G, Fernandez-Reyes MJ, Hevia C, Bajo MA, Castro MJ, Cirugeda A, et al: Factors influencing peritoneal transport parameters during the first year on peritoneal dialysis: peritonitis is the main factor. Nephrol Dial Transplant 2005; 20: $1201-1206$. 